\title{
Pediatric Nasolacrimal Duct Obstruction
}

\author{
Shani Golan and Gary J Lelli Jr \\ Department of Ophthalmology, Weill Cornell Medical College, New York Presbyterian Hospital, New York, NY, US
}

DOI: https://doi.org/10.17925/USOR.2018.11.2.87

$\mathrm{N}$ asolacrimal duct obstruction (NLDO) is common in the pediatric population and presents as persistent epiphora, recurrent conjunctivitis, crusting of the eyelids, and occasionally dacryocystits. It is typically congenital and occurs at the level of the valve of Hasner. Treatment options for pediatric NLDO include non-surgical and surgical procedures. Treatment may be carried out either in-office or in the operating room. In this review, we discuss the pathogenesis of pediatric NLDO and provide an update on current treatment options, including medical management with massage, which remains highly successful, and surgery, which may be warranted in children over the age of 3 years, those with anatomic variations and craniofacial anomalies, patients unresponsive to medical therapy and probing, and patients with acquired NLDO. In addition, we explore the benefits of new technologies and endoscopic approaches, including shorter operative time and no scarring, as well as the ability to perform bilateral procedures and simultaneously address any additional intranasal pathology.

\section{Keywords}

Nasolacrimal duct obstruction, congenital nasolacrimal duct obstruction, dacryocele, pediatrics

Disclosures: Shani Golan and Gary J Lelli Jr have nothing to declare in relation to this article.

Review Process: Double-blind peer review.

Compliance with Ethics: This study involves a review of the literature and did not involve any studies with human or animal subjects performed by any of the authors.

Authorship: All named authors meet the International Committee of Medical Journal Editors (ICMJE) criteria for authorship of this manuscript, take responsibility for the integrity of the work as a whole, and have given final approval to the version to be published.

open Access: This article is published under the creative Commons Attribution Noncommercial License, which permits any noncommercial use, distribution, adaptation, and reproduction provided the original author(s) and source are given appropriate credit. (c) The Authors 2018.

Received: March 29, 2018

Accepted: October 4, 2018

Citation: US Ophthalmic Review. 2018;11(2):87-90

Corresponding Author: Dr Shani Golan, Department of Ophthalmology, Weill Cornell Medical College, New York Presbyterian Hospital, 1305 York Avenue, New York, NY 10021, US. shanigola2@gmail.com

Support: No funding was received in the publication of this article.
Nasolacrimal duct obstruction (NLDO) is common in the pediatric population. The anatomic location of obstruction may be either pre- or post-saccal. It is typically congenital and occurs due to the persistence of a membrane at the level of the valve of Hasner in the distal nasolacrimal duct. ${ }^{\text {O Other }}$ causes include post-traumatic obstruction of the lacrimal system (in cases of canalicular laceration, a pre-saccal blockage may occur), presence of associated systemic anomalies, and acquired causes of NLDO ${ }^{2,3}$ The incidence is higher in children with craniofacial abnormalities. ${ }^{4}$

The clinical presentation of pediatric NLDO is usually in the form of epiphora (which affects up to $20 \%$ of children), ${ }^{5}$ sticky eyes, and recurrent conjunctivitis and crusting of the eyelids. At times, there is a swelling below the level of medial canthus (lacrimal mucocoele). If the mucococele becomes infected, there is associated warmth, tenderness and erythema. If the dacryocystitis is severe, rupture of the infected sac may occur through the skin potentially resulting in a lacrimal fistula. When pressure is applied to the lacrimal sac, there may be reflux of mucoid or mucopurulent material from the punctum.

In this review paper, we discuss the anatomy of the nasolacrimal system, pathogenesis of pediatric NLDO and provide an update on current treatment options.

\section{Anatomy of the nasolacrimal system}

The tears are drained through the upper and lower punctums, through the inferior and superior canaliculus to the common canaliculus, which drains into the lacrimal sac. Within the junction between the common canaliculus and the lacrimal sac is the valve of Rosenmuller. This is a one-way valve that prevents reflux from the lacrimal sac to the puncta. The lacrimal sac drains inferiorly to the nasolacrimal duct and from there into the inferior meatus of the nose which itself is partially covered by a mucosal fold known as the valve of Hasner., ${ }^{1,2}$

The lacrimal passages consist of a bony passage, and a membranous one. The first is formed anteriorly by the frontal process of the maxilla, and posteriorly by the lacrimal bone. The membranous lacrimal passages include the lacrimal canaliculus, the lacrimal sac, and the nasolacrimal duct and a membranous lacrimal.

\section{Epiphora in the pediatric population}

Congenital nasolacrimal duct obstruction (CNLDO) is the most common cause of pediatric epiphora and is discussed in this review. Dacryocele is another common mechanism and is discussed later. Other causes of pediatric epiphora have been found in around $4 \%$ of cases ${ }^{6}$ and include pre-saccal etiologies such as proximal lacrimal dysgenesis, punctal agenesis and canalicular wall dysgenesis. 
Several series on punctal and canalicular dysgenesis noted the mean age of presentation to be older than CNLDO cases (3.6-6.8 years)., ${ }^{6,7}$ These various CNLDO differential diagnoses should be thoroughly evaluated before attributing the cause to a cNLDO (a post-saccal obstruction) as the required treatment differs.

\section{Congenital nasolacrimal duct obstruction}

cNLDO occurs in approximately $6-20 \%$ of newborns. ${ }^{8}$ Often in these cases, obstructions resolve spontaneously or with medical treatment during the first year of life; however, cases that are not resolved typically require surgical intervention. ${ }^{9}$ In recent years, several multicenter studies conducted by the Pediatric Eye Disease Investigator Group (PEDIG) have been published on CNLDO, including studies reporting on the association between CNLDO and ametropia/amblyopia, as well as the introduction of new surgical techniques and instrumentation to treat the condition. ${ }^{10-12}$

The development of the lacrimal system begins by the fifth week of gestation. A lumen is formed in the lacrimal cord, and cavitation of the inferior meatal lamina occurs by the 10th week. Subsequently, the canalization of the lacrimal cord enables communication with the inferior meatus from the sixth fetal month to beyond term. If this fails to occur, a membranous barrier forms at the valve of Hasner, which resolves spontaneously in 85-95\% of cases by 1 year of age. ${ }^{1,3}$

A recent study using high-resolution computed tomography showed the obstruction to be either a persistence of a membrane at the distal end of the duct, bony obstruction, or narrowing of the inferior meatus with apposition of the nasal mucosa. ${ }^{13}$

\section{Dacryocele}

A dacryocele occurs in approximately one in 3,900 live births..$^{14}$ In addition to the typical obstruction at the valve of Hasner, these neonates have a ball-valve effect at the level of the valve of Rosenmuller (juncture of the common canaliculus and the lacrimal sac in a pre-saccal location), resulting in distention of the tear sac. A dacryocele will appear as a firm blue swelling in the lower lid just below the medial canthus and can be detected prenatally on ultrasound and magnetic resonance imaging. ${ }^{14}$ It occurs most often in females ${ }^{15}$ and is bilateral in $25 \%$ of patients. ${ }^{15,16}$ Infection ensues in $24-60 \%$ of cases. $^{16}$

Like cNLDO, a dacryocele has a high rate of spontaneous resolution; 50\% of the dacryoceles identified prenatally resolve prior to birth. ${ }^{15,16}$ Tear sac massage and administration of topical antibiotics may result in resolution in up to $76 \%$ of cases. ${ }^{16}$ Endoscopic excision of the associated intranasal cyst increases the success rate to above $95 \% .^{16}$

\section{Treatment of pediatric NLDO}

NLDO has a high rate of resolution without surgery. In one observational study, utilizing medical treatment only, the rate of NLDO resolution by 1 year of age was $80 \%$ at 3 months old, $70 \%$ at 6 months old, and $52 \%$ at 9 months old. ${ }^{17}$ PEDIG found that $66 \%$ of infants aged 6-10 months resolved with non-surgical management within a 6-month timeframe. ${ }^{8}$ Spontaneous resolution beyond 1 year of age is also possible, as evidenced by Yound et al., who found that $41 \%$ of children with congenital NLDO experienced spontaneous resolution during the second year of life (after 1 year of age, but before reaching 2 years). ${ }^{18}$

\section{Medical treatment}

Medical treatment of NLDO consists of compression or massage of the nasolacrimal sac alongside topical antibiotics when discharge is present. Massaging the nasolacrimal sac in a downward fashion will produce hydrostatic pressure, rupturing the membranous obstruction at the valve of Hasner.

Downward massage of the nasolacrimal sac is more effective than simple massage or no massage. ${ }^{19,20} \mathrm{~A}$ recent study found that the success rate of the Crigler maneuver, which consists of occluding the puncta and canalicular system and then pressing over the sac, was $56 \%$ in children aged under 2 months, $46 \%$ in children aged 2-6 months, and 28\% in children older than 6 months. $^{2}$

\section{Probing of the nasolacrimal duct}

The most common surgical procedure used to treat NLDO in children is probing of the nasolacrimal system. Probing is a safe and effective technique in treating cNLDO; however, the optimal timing for undertaking the procedure remains controversial. On one hand, spontaneous resolution can occur after 13 months of age,, 17 and some authors propose that it can still happen up to 48 months of age; ${ }^{\prime 8}$ on the other, probing is thought to be less successful at an older age. The procedure can be done in the office with topical anesthesia (usually reserved for younger children aged 6-9 months) or in the surgical unit under general anesthesia (for children aged over 12 months). Several studies have demonstrated that immediate office-based probing is not associated with a statistically significant reduction in number of symptomatic months compared to probings performed later in a surgical facility under general anesthesia. However, although office-based probing is marginally less expensive than surgical probing, it was also found to carry a slightly lower success rate. ${ }^{8-10}$ The decision on whether to probe early or to probe after 1 year of age should be based upon the treating ophthalmologist's experience and expertise in probing.

Overall, the reported success rate of probing is in the $80-90 \%$ range in children aged less than 3 years, ${ }^{9-11}$ and remains high until 3 years of age, at which point success rates start to decrease. ${ }^{22}$ Non-randomized prospective studies by PEDIG in children younger than 4 years with cNLDO found the success rate for probing to be $78 \%,{ }^{9} 82 \%$ when combined with balloon catheter dilation, ${ }^{11}$ and $91 \%$ with nasolacrimal duct intubation. ${ }^{10}$ The success rate is lower with bilateral disease or when more than one clinical sign of NLDO is present, but does not appear to be related to age within the range of 6 to $<15$ months. ${ }^{8}$

With the introduction of endoscopic techniques in nasolacrimal system surgical interventions, endoscopic probing was suggested as an alternate to the conventional blinded probing that may result in false passage. Endoscopic probing allows visualization of the lower end of the nasolacrimal system and of nasal anomalies such as the atresia, cyst, stenosis, and false probe passage. Additionally, direct visualization of the inferior turbinate allows observation of an impacted turbinate, which can in turn affect the success of probing. Several studies comparing the two techniques in children with cNLDO found a significantly higher success rate with endoscopic probing, especially in older children, a likely consequence of the ability to observe and treat associated problems. ${ }^{23,24}$

Silicone tube intubation for the treatment of CNLDO is a well-established treatment option in the management of cNLDO after failed probing 
and irrigation. Several large studies report success rates ranging from 82-97\% following silicone intubation. ${ }^{25-27}$ Controversy exists as to whether nasolacrimal intubation is more likely to fail in older children.26 In a comparative study of simple probing versus intubation as a secondary procedure, patients treated with intubation were significantly more likely to achieve a successful outcome. ${ }^{27}$

Bicanalicular and monocanalicular intubation are equally successful in the treatment of CNLDO. ${ }^{28} \mathrm{~A}$ monocanalicular tube is easier to insert and remove, and therefore is more commonly used in the pediatric population. Most lacrimal intubation systems require intraoperative retrieval of the tube from the nose. However, monocanalicular tubes may be removed proximally after the tube is placed, allowing office-based removal in many children.29 Lacrimal tubes are usually removed after 2-6 months. Whereby children under 2 years of age do well with tube removal at 6 weeks, older children benefit from a longer period of intubation and may have an increased chance for success if the tube is left in place for at least 3 months. ${ }^{30}$ Several conditions may necessitate early tube removal, such as a corneal or conjunctival abrasion from the tube, granuloma formation, and punctal erosion. Monocanalicular and Masterak ${ }^{\circledR}(\mathrm{FCl}$ Ophthalmics Inc. Pembroke, MA, US) tubes are held in place by a collarette on the footplate, which is placed in the puncta. This footplate may become loose or fall out spontaneously, so care must be taken when dilating the puncta not to enlarge the puncta to the point where it will not hold the footplate of the tube firmly. Bicanalicular tubes, if placed through a bolster or retinal sponge in the nose, may require removal under a brief general anesthetic.

\section{Pediatric dacryocystorhinostomy}

Dacryocystorhinostomy (DCR) in children is indicated in cases of NLDO that are unresponsive to medical therapy, probing, balloon dilation or intubation. When asked about timing for surgical intervention, 79\% of members of the American Association for Pediatric Ophthalmology and Strabismus replied that they start recommending surgical intervention under general anesthesia for unresolved cNLDO at the age of 13 months. ${ }^{31}$

External DCR has conventionally been the preferred treatment option for CNLDO. In a study of external DCR, symptoms were improved in all 134 cases and complete cure was achieved in 96\%, with no immediate post-operative complications and only few (3\%) short-term complications. ${ }^{32}$ Endonasal DCR has increasingly become popular over the last decade with an evaluated success rate of $88-100 \%$. ${ }^{33,34}$ Though technically difficult in small children, endonasal DCR offers several advantages over the external approach: it can be performed in acute conditions, it avoids facial scarring, it causes less disruption of the medial canthal anatomy, it does not disturb the lacrimal pump mechanism, it decreases operative time, and it may even decrease post-operative discomfort. ${ }^{34,35}$ Additionally, endonasal DCR can simultaneously treat any associated nasal pathology and can be performed bilaterally under general anesthesia as an outpatient procedure. However, disadvantages associated with endonasal DCR include the significant learning curve of working in a narrow nasal space in pediatric patients and technical difficulties encountered due to existing anatomical variations. When comparing the success rate of endonasal and external DCR in the pediatric population, endoscopic DCR gives similar results compared to the external approach. ${ }^{34-36}$

In 2011, Uysal et al. reported on their experiences with the endocanalicular diode laser procedure. Of the 18 cases presented, 100\% achieved anatomical success (defined by patency of ostium on nasal endoscopy); the clinical success rate (resolution of epiphora) was $85 \%{ }^{37}$

In addition, an ultrasonic endoscopic DCR is emerging as an alternative modality for managing NLDO. The principal advantage of this technique is the safety of surrounding soft tissues during osteotomy. In a recent study published at the 6-month follow-up, anatomical and functional successes were noted in $93.1 \%$ and $88.6 \%$, respectively. ${ }^{38}$

\section{Conclusion}

Our review discusses the clinical aspects of pediatric NLDO. Medical management with massage using the crigler maneuver remains highly successful. Probing of the lacrimal system is also highly effective until at least 3 years of age. ${ }^{18-20}$ Resolution with medical management is possible beyond 1 year of age, thus it is reasonable to continue with medical management until approximately 15 months of age. Any failed probings should be treated under general anesthesia with balloon catheter dilation and/or nasolacrimal duct intubation. Furthermore, children with NLDO need to be followed until 3-4 years of age to ensure that anisometropic amblyopia does not develop.

Some situations may warrant formal DCR surgery, these include: children over the age of 3 years, those with anatomic variations and craniofacial anomalies, patients unresponsive to medical therapy and probing, and patients with acquired NLDO. ${ }^{31-32}$ While external DCR remains a successful and viable option, new technologies and endoscopic approaches afford the patient shorter operative time and no scarring. In addition, these approaches enable performance of bilateral procedures and allow the physician to simultaneously address any additional intranasal pathology. $\square$
1. Cassady JV. Developmental anatomy of nasolacrimal duct. AMA Arch Ophthalmol. 1952:47:141-58.

2. Komínek P, Cervenka S. Pediatric endonasal dacryocystorhinostomy: a report of 34 cases. Laryngoscope. 2005;115:1800-3.

3. Olitsky SE. Update on congenital nasolacrimal duct obstruction. Int Ophthalmol Clin. 2014;54:1-7.

4. Berk AT, Saatci AO, Erçal M.D, et al. Ocular findings in 55 patients with Down's syndrome. Ophthalmic Genet. 1996;17:15-9.

5. MacEwen CJ, Young JD. Epiphora during the first year of life. Eye (Lond). 1991:5:596-600.

6. Kamal S, Ali MJ, Gupta A, Naik MN. Lacrimal and nasal masquerades of congenital nasolacrimal duct obstructions: etiology, management, and outcomes. Int Ophthalmol. 2015;35:807-10.

7. Ali MJ, Naik MN. Canalicular wall dysgenesis: the clinical profile of canalicular hypoplasia and aplasia associated systemic and acrimal anomalies, and clinical implications. Ophthalmic Plast Reconstr Surg. 2013:29:464-8

8. Pediatric Eye Disease Investigator Group. Resolution of congenital nasolacrimal duct obstruction with nonsurgical management Arch Ophthalmol. 2012:130:730-4.

9. Pediatric Eye Disease Investigator Group, Repka MX, Chandler DL, et al. Pediatric Eye Disease Investigator Group. Primary treatment of nasolacrimal duct obstruction with probing in children younger than 4 years. Ophthalmology. 2008;115:577-84.e3.

10. Pediatric Eye Disease Investigator Group, Repka MX, Melia BM et al. Primary treatment of nasolacrimal duct obstruction with nasolacrimal duct intubation in children younger than 4 years of age. J AAPOS. 2008:12:445-50

11. Pediatric Eye Disease Investigator Group, Repka MX, Wallace DK, et al. Primary treatment of nasolacrimal duct obstruction with balloon catheter dilation in children younger than 4 years of age. J AAPOS. 2008;12:451-5.

12. Matta NS, Silbert DI. High prevalence of amblyopia risk factors in preverbal children with nasolacrimal duct obstruction. J AAPOS. 2011;15:350-2.

13. Weiss AH, Baran F, Kelly J. Congenital nasolacrimal duct obstruction. Delineation of anatomic abnormalities with 3-dimensional reconstruction. Arch Ophthalmol. 2012;130:842-8.
14. Mackenzie PJ, Dolman PJ, Stokes J, Lyons CJ. Dacryocele diagnosed prenatally. Br J Ophthalmol. 2008:92:437-8.

15. Shekunov J, Griepentrog GJ, Diehl NN, Mohney BG. Prevalence and clinical characteristics of congenital dacryocystocele. J AAPOS. 2010;14:417-20.

16. Paysee EA, Coats DK, Bernstein JM, et al. Management and complications of congenital dacryocele with concurrent intranasal mucocele. J AAPOS. 2000;4:46-53.

17. Schnall BM, Christian CJ. Conservative treatment of congenital dacryocele. J Pediatr Ophthalmol Strabismus. 1996:33:219-22.

18. Paul TO. Medical management of congenital nasolacrimal duct obstruction. J Pediatr Ophthalmol Strabismus. 1985;22:68-70.

19. Yound JD, MacEwen CJ, Ogston SA. Congenital nasolacrimal duct obstruction in the second year of life: a multicenter trial of management. Eye. 1996;10:485-91.

20. Crigler LW. The treatment of congenital dacryocystitis. J Am Med AssoC. 1923;81:23-4.

21. Stolovitch C, Michaeli A. Hydrostatic pressure as an office procedure for congenital nasolacrimal duct obstruction. 
J AAPOS. 2006;10:269-72.

22. Arora S, Koushan K, Harvey J. Success rates of primary probing for congenital nasolacrimal obstruction in children. J AAPOS. 2012;16:173-6.

23. Galindo-Ferreiro A, Khandekar R, Akaishi PM, et al. Success rates of endoscopic-assisted probing compared to conventional probing in children 48 months or older. Semin Ophthalmol. 2018:33:435-42.

24. Galindo-Ferreiro A, Akaishi P, Cruz A, et al. Success rates of conventional versus endoscope-assisted probing for congenital nasolacrimal duct obstruction in children 12 years and younger. J Pediatr Ophthalmol Strabismus. 2016;53:292-9

25. Leone CR Jr, Van Gemert JV. The success rate of silicone intubation in congenital lacrimal obstruction. Ophthalmic Surg. 1990;21:90-2.

26. Lim CS, Martin F, Beckenham T, Cumming RG. Nasolacrimal duct obstruction in children: outcome of intubation. J AAPOS. 2004;8:466-72

27. Napier ML, Armstrong DJ, MCLoone SF, MCLoone EM. Congenital nasolacrimal duct obstruction: comparison of two different treatment algorithms. J Pediatr Ophthalmol Strabismus. 2016;53:285-91.

28. Andalib $D$, Gharabaghi $D$, Nabai R, Abbaszadeh $M$. Monocanalicular versusbicanalicular silicone intubation for congenital nasolacrimal duct obstruction. J AAPOS 2010;14:421-4.

29. Fayet B, Katowitz WR, Racy E, et al. Pushed monocanalicular intubation: an alternative stenting system for the management of congenital nasolacrimal duct obstruction. J AAPOS. 2012;16:468-72.

30. El-Essawy R. Effect of timing of silicone tube removal on the result of duct intubation in children with congenital nasolacrimal duct obstruction. Ophthalmic Plast Reconstr Surg. 2013:29:48-50.

31. Dotan $G$, Nelson LB. Congenital nasolacrimal duct obstruction: common management policies among pediatricophthalmologists. J Pediatr Ophthalmol Strabismus. 2015;52:14-9.

32. Barnes EA, Abou-Rayyah Y, Rose GE. Pediatric dacryocystorhinostomy for nasolacrimal duct obstruction. Ophthalmology. 2001;108:1562-4
33. Marfatia H, Shah K, Patil S, Parmar Y. Endonasal dacryocystorhinostomy in children: Our experience. Int J Surg. 2017;47:91-5.

34. Chan W, Wilcsek G, Ghabrial R, et al. Pediatric endonasal dacryocystorhinostomy: A multicenter series of 116 cases. Orbit. 2017;36:311-6.

35. Komínek P, Cervenka S, Matousek P, et al. Primary pediatric endonasal dacryocystorhinostomy-a review of 58 procedures. Int J Pediatr Otorhinolaryngol. 2010;74:661-4.

36. Gioacchini FM, Alicandri-Ciufelli M, Kaleci S, Re M. The outcomes of endoscopic dacryocystorhinostomy in children: A systematic review. Int J Pediatr Otorhinolaryngol. 2015;79:947-52.

37. Uysal IO, Ozçimen M, Yener HI, Kal A. Pediatric endocanalicular diode laser dacryocystorhinostomy: results of a minimally invasive surgical technique. Eur Arch Otorhinolaryngol. 2011;268:1283-8.

38. Ali MJ, Singh M, Chisty N, Kamal S, Naik MN. Endoscopic ultrasonic dacryocystorhinostomy: clinical profile and outcomes. Eur Arch Otorhinolaryngol. 2016;273:1789-93. 